\title{
Lignin and Cellulose Extraction from Vietnam's Rice Straw Using Ultrasound-Assisted Alkaline Treatment Method
}

\author{
Ngo Dinh Vu, ${ }^{1}$ Hang Thi Tran,, ${ }^{1}$ Nhi Dinh Bui, ${ }^{2}$ Cuong Duc Vu, ${ }^{1}$ and Hung Viet Nguyen ${ }^{3}$ \\ ${ }^{1}$ Faculty of Chemical Technology, Viet Tri University of Industry, Tien Kien, Lam Thao, Phu Tho, Vietnam \\ ${ }^{2}$ Faculty of Environmental Technology, Viet Tri University of Industry, Tien Kien, Lam Thao, Phu Tho, Vietnam \\ ${ }^{3}$ Faculty of Chemistry, University of Science, Vietnam National University, 19 Le Thanh Tong, Hoan Kiem, Hanoi, Vietnam
}

Correspondence should be addressed to Ngo Dinh Vu; vungo@vui.edu.vn

Received 20 July 2017; Revised 14 September 2017; Accepted 27 September 2017; Published 25 October 2017

Academic Editor: Hossein Roghani-Mamaqani

Copyright (C) 2017 Ngo Dinh Vu et al. This is an open access article distributed under the Creative Commons Attribution License, which permits unrestricted use, distribution, and reproduction in any medium, provided the original work is properly cited.

\begin{abstract}
The process of cellulose and lignin extraction from Vietnam's rice straw without paraffin pretreatment was proposed to improve economic efficiency and reduce environmental pollution. Treatment of the rice straw with ultrasonic irradiation for 30 min increased yields of lignin separation from $72.8 \%$ to $84.7 \%$. In addition, the extraction time was reduced from $2.5 \mathrm{~h}$ to $1.5 \mathrm{~h}$ when combined with ultrasonic irradiation for the same extraction yields. Results from modern analytical methods of FT-IR, SEM, EDX, TG-DTA, and GC-MS indicated that lignin obtained by ultrasound-assisted alkaline treatment method had a high purity and showed a higher molecular weight than that of lignin extracted from rice straw without ultrasonic irradiation. The lignin and cellulose which were extracted from rice straw showed higher thermal stability with $5 \%$ degradation at a temperature of over $230^{\circ} \mathrm{C}$. The ultrasonic-assisted alkaline extraction method was recommended for lignin and cellulose extraction from Vietnam's rice straw.
\end{abstract}

\section{Introduction}

As the world's most abundant renewable resource, lignocellulosic biomass has been acknowledged for potential use to produce chemicals and biomaterials. Lignocellulose is a low cost biomass that is abundantly available. Its main constituents are cellulose, hemicellulose, and lignin.

Cellulose is mainly used to produce paperboard and paper. Smaller quantities are converted into a wide variety of derivative products such as cellophane and rayon $[1,2]$. Conversion of cellulose from energy crops into biofuels such as cellulosic ethanol is under investigation as an alternative fuel source [3-5]. Another growing application of cellulose is in composite materials as reinforcement in polymeric materials $[6,7]$.

Lignin, making up $10-25 \%$ of lignocellulosic biomass, depending on the kind of plant, is the second most abundant natural polymer [8]. The areas in which lignin is applicable include emulsifiers, dyes, synthetic floorings, sequestering, binding, thermosets, dispersal agents, paints, and fuels for treatments of roadways [9-12].

The main methods of the extraction of lignin and cellulose from different sources historically explored are hydrothermal, acidic, alkaline, wet oxidation, ammonia fiber explosion, organosolv, and, most recently, ionic liquid pretreatment methods (which were reviewed elsewhere) [1315]. These extraction methods are expensive and energy intensive and utilize chemicals which require special disposal, handling, or production methods. In addition, materials for cellulose and lignin extraction are limited to straw of all kinds and timber for the limitation of technology. Extraction methods are only applied in laboratory, which seldom works in industrial production. How to break technology barrier is the key for cellulose and lignin extraction on big scale. Therefore new technologies must provide methods with inconsiderable environmental and economic impacts and high efficiency [16].

Nowadays, ultrasound-assisted extraction is evaluated as a simpler and more effective alternative to conventional 


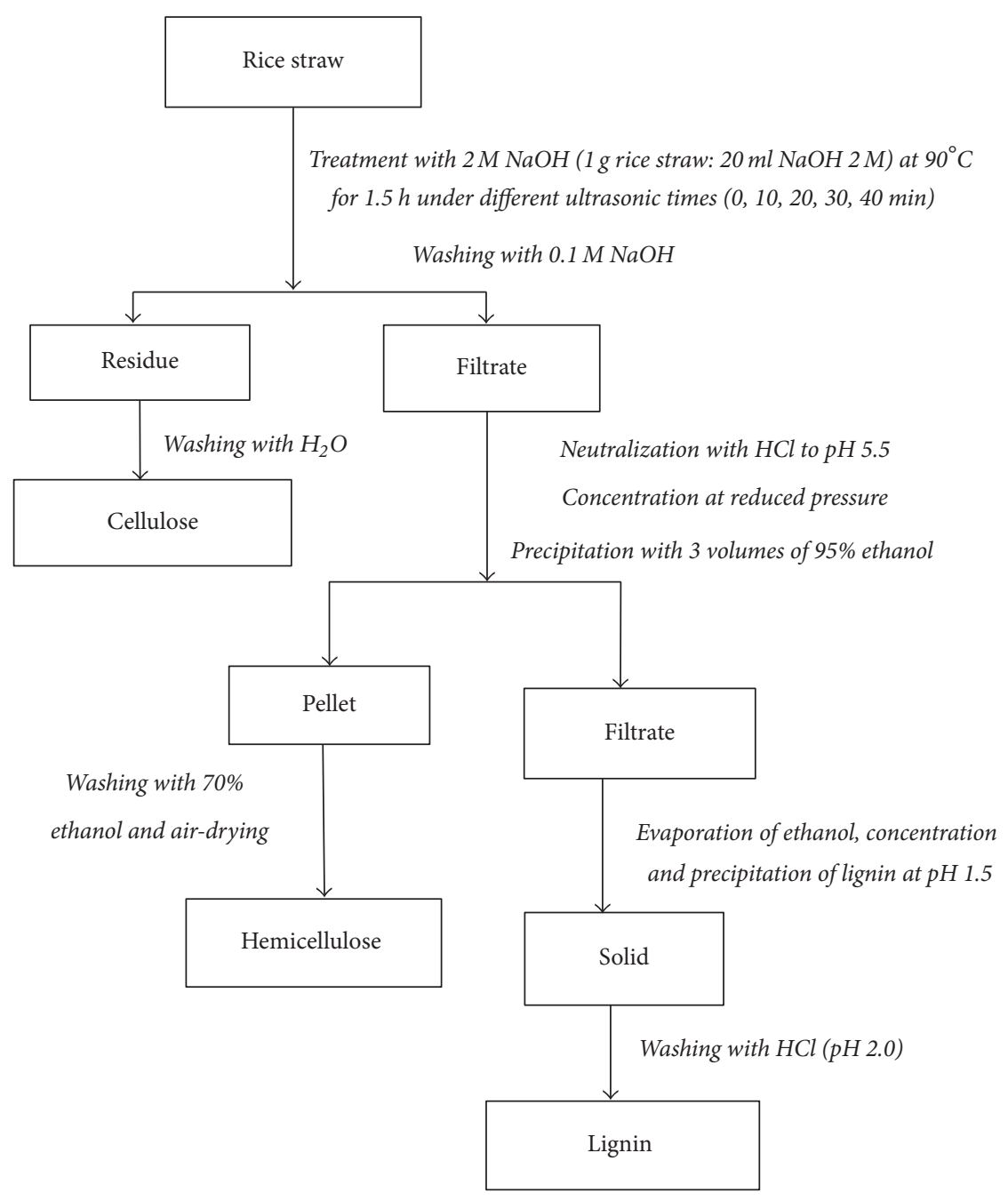

Scheme 1: Ultrasound-assisted extraction method of lignin and cellulose.

extraction methods for the extraction of lignin and cellulose from natural products $[17,18]$. Ultrasonication induces localized high temperature and pressure and results in the production of highly reactive free radicals, such as $\mathrm{OH}^{-}, \mathrm{H}^{+}$, and $\mathrm{H}_{2} \mathrm{O}_{2}$, thus enhancing chemical reactions. The sonomechanical effect of ultrasound enhances the penetration of the solvent and heat into cellular materials and thus improves the mass transfer; thus it also requires significant additional energy input. Ultrasound for pretreatment of lignocellulose was examined in conjunction with other methods $[19,20]$. But up to now, no research has combined ultrasound, alkalinity, and temperature to separate cellulose and lignin.

Vietnam is an agricultural country, producing about 45 million tons of grains annually; thus 54 million tons of rice straw is produced. However, most of the rice straw is burned on the open fields, causing serious environmental pollution. Therefore, the conversion of rice straw into valuable materials is essential. This paper gives an overview on investigation of the extraction method of lignin and cellulose from Vietnam's rice straw using the combination of ultrasound irradiation and chemical method under high temperature and alkaline concentration to reduce extraction time. The properties of obtained lignin and cellulose were also evaluated.

\section{Experimental Section}

2.1. Materials and Chemicals. Rice straw was provided by farmers in Tien Kien Commune, Lam Thao District, Phu Tho Province, Vietnam. The chemical agents $(\mathrm{NaOH}, \mathrm{HCl}$, and ethanol) were purchased from Merck Chemicals (Shanghai) Co., Ltd. All of the chemicals were reagent grade or higher in purity and were used on receipt without further purification.

2.2. Ultrasound-Assisted Alkaline Extraction Method of Lignin and Cellulose. The alkaline and ultrasound-assisted alkaline extraction of lignin and cellulose are shown in Scheme 1. The rice straw was first extracted with the ultrasound irradiation 
TABLE 1: Elemental composition in inner layer and outer layer of the rice straw.

\begin{tabular}{lcccccccc}
\hline \multirow{2}{*}{ Sample } & \multicolumn{9}{c}{ Content, \% } & \multicolumn{2}{c}{ } & \multicolumn{2}{c}{ Cl } & $\mathrm{K}$ & $\mathrm{Ca}$ \\
\hline Outer surface & $36.88 \pm 1.195$ & $46.52 \pm 0.849$ & $0.16 \pm 0.014$ & $0.22 \pm 0.021$ & $13.92 \pm 0.537$ & $0.715 \pm 0.092$ & $1.43 \pm 0.106$ & $0.17 \pm 0.035$ \\
Inner surface & $44.75 \pm 0.919$ & $45.99 \pm 2.666$ & $0.60 \pm 0.092$ & $0.09 \pm 0.077$ & $4.78 \pm 1.259$ & $0.65 \pm 0.014$ & $2.67 \pm 0.608$ & $0.28 \pm 0.007$ \\
\hline
\end{tabular}

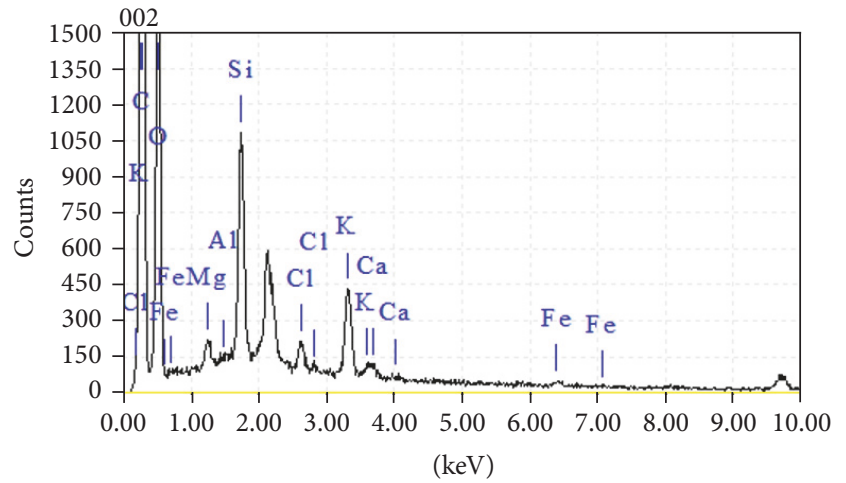

(a)

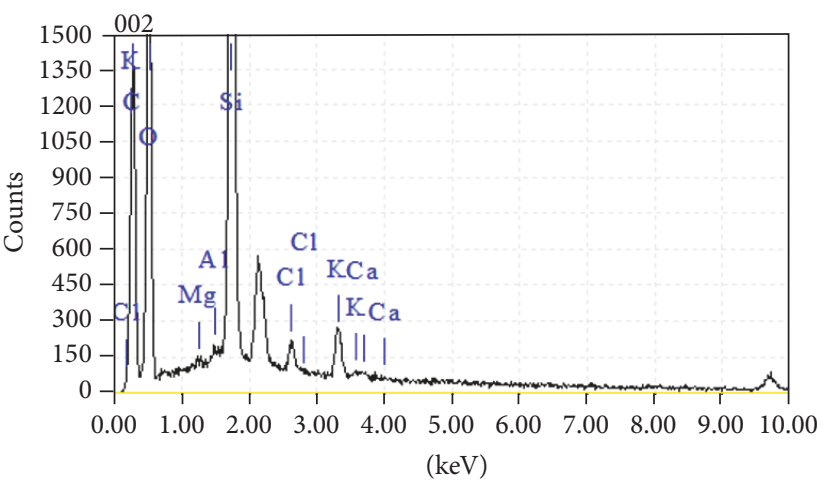

(b)

FIGURE 1: EDX spectra of (a) inner and (b) outer surface of Vietnam's rice straw.

by the Sonic system SOMERSET (England, $20 \mathrm{kHz}$ ) provided with a horn with ultimate power of $500 \mathrm{~W}$ and sonication time of $0,10,20,30$, and $40 \mathrm{~min}$ in $2 \mathrm{M} \mathrm{NaOH}$ aqueous solution at $90^{\circ} \mathrm{C}$. Then, the mixture was continuously stirred at $90^{\circ} \mathrm{C}$ for a total period of $1.5 \mathrm{~h}$. After that, the mixture was washed with $0.1 \mathrm{M} \mathrm{NaOH}$ to remove the remaining lignin on the cellulose surface. After the filtration on a nylon cloth, the residue rich in cellulose was further washed with distilled water and dried at $50^{\circ} \mathrm{C}$ for 24 hours. The hemicellulose was isolated from hydrolysates by precipitation of the acidified hydrolysate ( $\mathrm{pH}$ was adjusted to 5.5 with $\mathrm{HCl}$ solution) with three volumes of $95 \%$ ethanol for $6 \mathrm{~h}$. The pellets rich in the hemicellulose were filtered, washed with $70 \%$ ethanol, and air-dried. After the evaporation of ethanol, the alkali soluble lignin was obtained by precipitation at $\mathrm{pH} 1.5$ adjusted by $\mathrm{HCl}$. The solid rich in lignin was then washed with acidified solution pH 2.0 and freeze-dried. Yield of cellulose and lignin fractions is given on a dry weight basis related to the rice straw.

2.3. Physicochemical and Thermal Analysis of Cellulose and Lignin. The surface morphology and element contents of the straw were analyzed on a scanning electron microscope (SEM/EDX, JEOL JMS 6490, JEOL, Japan). The thermal stability of lignin and cellulose was determined on a thermal analyzer (TG-DTA: EXSTRAR6100, Seiko Instruments, Japan). Fiber size of cellulose was determined by scanning electron microscope (SEM: JEOL, Japan); surface tension of lignin was determined on the CAM 200 (KSV Instructions, Finland). The content of neutral sugar contained in lignin was determined by gas spectrometry (GC-MS: Clarus 500,
Perkin-Elmer, USA). The lignin content was determined by gel permeation chromatography (GPC: HLC8120, TOSOH, Japan) with polystyrene standards.

\section{Results and Discussion}

3.1. Rice Straw Composition. Many recent studies have focused on the general composition in a straw thread. According to Saha and Cotta, the elemental composition of wheat straw was as follows: $\mathrm{C}, 44 \% ; \mathrm{O}, 49 \% ; \mathrm{H}, 5 \% ; \mathrm{N}, 0.92 \%$; and other components with small content [21]. In this study, obtained results from the analysis showed that the rice straw that contains the content of the inner and outer layers was different (Figure 1 and Table 1).

It can be seen from Figure 1 and Table 1 that the contents of $\mathrm{O}$ and $\mathrm{Cl}$ in two surfaces are not so different and the contents of elements $\mathrm{C}, \mathrm{Mg}$, and $\mathrm{Ca}$ of inner surface are larger than those of outer surface but, however, the contents of other elements of outer surface are higher than those of inner surface, especially Si.

The contents of lignin and cellulose in the rice straw of this study are 19.02 and $39.2 \%$, respectively.

3.2. Yield, Purity, and Molecular Properties. There are many research papers that show the separation process of cellulose and lignin from wheat straw using a solvent mixture of toluene/ethanol to remove paraffin (pretreated) before extraction. We have compared the pretreated and nonpretreated methods before the alkaline treatment, but the yield extraction and lignin or cellulose properties were not 
TABLE 2: The yield of lignin obtained by alkaline and ultrasonicassisted alkaline extraction of rice straw with $2 \mathrm{M} \mathrm{NaOH}$ at $90^{\circ} \mathrm{C}$ for $1.5 \mathrm{~h}$.

\begin{tabular}{lccccc}
\hline & \multicolumn{5}{c}{ Ultrasonic time, min } \\
\hline Yields, \% & 0 & 10 & 20 & 30 & 40 \\
Lignin & 72.8 & 72.9 & 78.6 & 84.7 & 84.9 \\
\hline
\end{tabular}

different. Therefore, we propose the process of cellulose and lignin separation from rice straw without paraffin pretreatment to improve economic efficiency, reduce environmental pollution, and develop potential industrial applications.

Straws are poorly digested by ruminants because of their high cell-wall content. Alkaline treatment disrupts the cell wall by dissolving hemicellulose, lignin, and silica, by hydrolysing uronic and acetic acid esters, and by swelling cellulose [22]. Furthermore, the alkaline solution breaks $\alpha$ ether bonds between lignin and hemicellulose and ester bonds between lignin and hydroxycinnamic acids such as $\mathrm{p}$ coumaric acid and ferulic acid [23]. More importantly, alkaline treatment is a promising approach that does not affect the environment. Through this process, lignocellulose can be broken down into lignin, hemicellulose, and cellulose, which are materials for valuable products. Sun and Tomkinson have published a process of lignin separation from wheat straw with $0.5 \mathrm{M} \mathrm{KOH}$ at $35^{\circ} \mathrm{C}$ for $2.5 \mathrm{~h}$, but the yield was only $43.9 \%$ [24]. Xiaoa and coworkers have announced the separation of lignin from straw with $1 \mathrm{M} \mathrm{NaOH}$ solution at $30^{\circ} \mathrm{C}$. The yield was only $68.3 \%$ for long period of 18 hours [25]. In this study, the alkaline solution with high concentration $2 \mathrm{M} \mathrm{NaOH}$, high temperature $90^{\circ} \mathrm{C}$, and the ultrasound irradiation were used to increase lignin separation efficiency and reduce separation time. Separation yields of lignin were summarized in Table 2. As expected, treatment of the rice straw with $2 \mathrm{M} \mathrm{NaOH}$ without ultrasound irradiation at $90^{\circ} \mathrm{C}$ for $1.5 \mathrm{~h}$ and with ultrasonic irradiation for 10, 20, 30, and $40 \mathrm{~min}$ increased yields of separation of lignin $(72.8 \%, 72.9 \%$, $78.6 \%, 84.7 \%$, and $84.9 \%$, resp.).

It can be seen from Table 2 that there are not much differences in extraction yields of lignin and cellulose between ultrasound-assisted alkaline extractions for $0 \mathrm{~min}$ and $10 \mathrm{~min}$ and $30 \mathrm{~min}$ and $40 \mathrm{~min}$. This implied that ultrasonic irradiation time is a main parameter affecting the lignin and cellulose yields under the conditions used. Obviously, between the irradiation times 10 and $30 \mathrm{~min}$ extraction yields of lignin were increased from $72.9 \%$ to $84.7 \%$, respectively. Approximately all of the total lignin and cellulose in rice straw were separated during the alkaline extraction at sonication time of $30 \mathrm{~min}$. Thus, the application of sonication for $30 \mathrm{~min}$ resulted in raising the lignin yield by $12.3 \%$ in comparison to the alkaline extraction procedure without ultrasound assistance.

The higher efficiency of the ultrasound-assisted alkaline extractions can be explained by the mechanical action of ultrasound on the cell walls resulting in an increased accessibility and extractability of the lignin and cellulose component. The alkaline extractions with ultrasonic irradiation
TABLE 3: The molecular weight and the polydispersity of lignin obtained at different ultrasonic times.

\begin{tabular}{lccccc}
\hline & \multicolumn{5}{c}{ Ultrasonic time, min } \\
& 0 & 10 & 20 & 30 & 40 \\
\hline$M_{w}$ & 2560 & 2620 & 3210 & 3720 & 2990 \\
$M_{n}$ & 1350 & 1370 & 1550 & 1690 & 1520 \\
$M_{w} / M_{n}$ & 1.89 & 1.91 & 2.07 & 2.20 & 1.97 \\
\hline
\end{tabular}

under the conditions used have a greater effect on the cleavage of the ether bonds between lignin and hemicelluloses from the cell walls of rice straw than the alkaline treatment without ultrasonic assistance. The major ether linkages, that is, $\beta$ $\mathrm{O}-4$ bonds between lignin interunity linkages and $\alpha$-O-4 ether linkages between lignin and hemicelluloses, can be homolytically ruptured or cleaved to some extent by the ultrasonic irradiation [26]. Mass spectrometry of lignin obtained by ultrasonic irradiation for $30 \mathrm{~min}$ showed that the concentrations of xylose, glucose, arabinose, and galactose contained in lignin were $0.39,0.15,0.12$, and $0.04 \%$, respectively. The results indicated that lignin had a high purity and xylose was the major sugar component in lignin, while galactose content was very small.

Some works have published the average molecular weights $\left(M_{w}\right)$ and the average number weight $\left(M_{n}\right)$ of lignin which was extracted from wheat straw, which ranged from 1000 to $23600 \mathrm{Da}$ and from 700 to $5268 \mathrm{Da}$, respectively, depending on the method and separation conditions [27]. The values of $M_{w} M_{n}$ and the polydispersity $\left(M_{w} / M_{n}\right)$ of lignin in this study are given in Table 3.

As shown in Table 3, the lignin obtained by the ultrasoundassisted alkaline extraction method for 10-30 min had a slightly higher $M_{w}$ (from 2620 to $3720 \mathrm{Da}$ ) than that of the lignin obtained by alkaline method without ultrasonic irradiation $\left(M_{w}=2560 \mathrm{Da}\right)$; the observed phenomenon indicated an increase in solubilization of large molecular size lignins under the ultrasonic conditions used. The reason for this increase in $M_{w}$ is probably the condensation reaction between the lignin structures under ultrasound irradiation conditions given. In contrast, as the irradiation time was further increased from 30 to $40 \mathrm{~min}, M_{w}$ decreased from 3720 to $2990 \mathrm{Da}$. The decrease in $M_{w}$ is assigned to the cleavage of the $\beta$-O- 4 linkages between the lignin precursors under a relatively longer sonication period.

Fiber size is one of the factors that affect the properties of the cellulose material. The smaller the size of cellulose fibers is, the better their mechanical properties will be. The size of cellulose fiber extracted from rice straw by the ultrasoundassisted alkaline extraction method is shown in Figure 2. The rice straw is a dense block (Figures 2(a) and 2(b)), but the bonds between lignin, hemicellulose, cellulose, and other components have been separated after alkaline treatment at $90^{\circ} \mathrm{C}$ for 1.5 hours and ultrasonic irradiation for $30 \mathrm{~min}$. The result is that cellulose fiber has an average diameter of about $5 \mu \mathrm{m}$ with a relatively considerable roughness (Figure 2(c)). This result again confirmed the removal of lignin, hemicellulose, and other impurities from the cellulose fiber surface. 


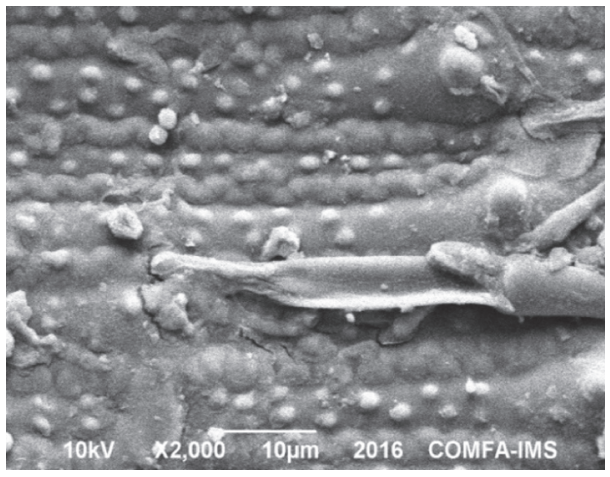

(a)

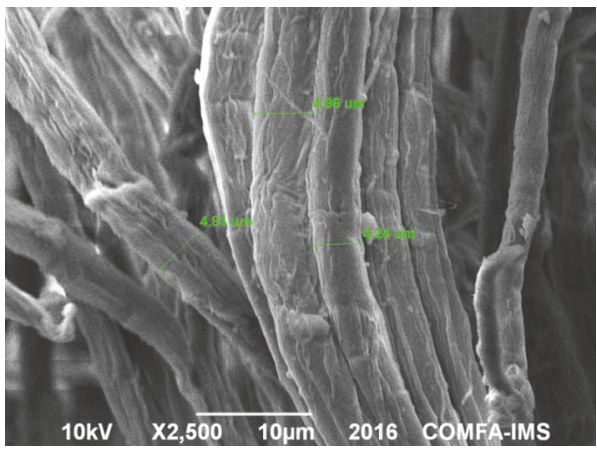

(c)

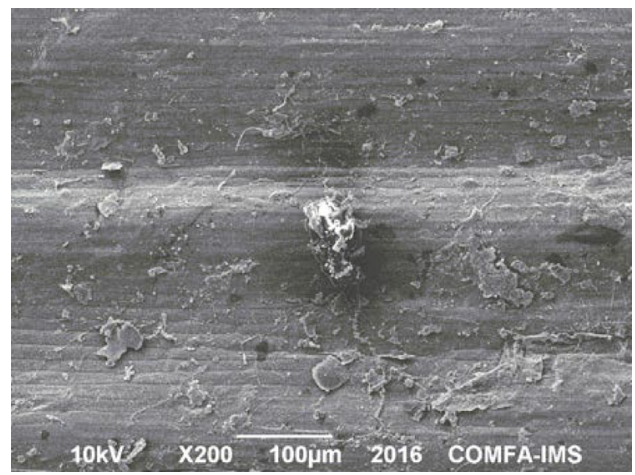

(b)

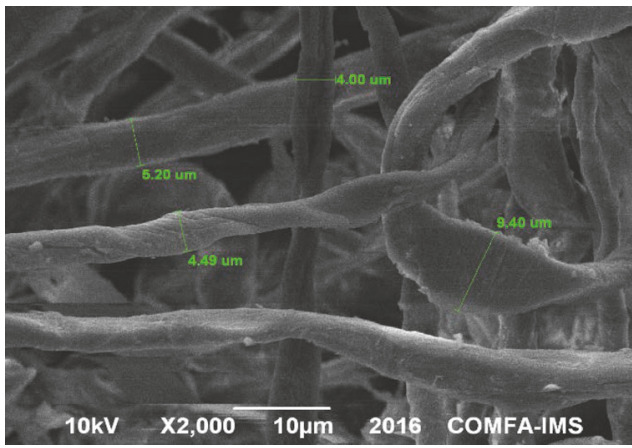

(d)

FIGURE 2: SEM of rice straw: outer layer (a), inner layer (b), cellulose fiber extracted by the ultrasound-assisted alkaline extraction method (c), and cellulose fiber extracted without ultrasound (d).

The FTIR spectra of the cellulose extracted by the ultrasound-assisted extraction method are shown in Figure 3. Results showed specific peaks of cellulose around 3300, 2900, 1400 , and $900 \mathrm{~cm}^{-1}$. The signal at $902 \mathrm{~cm}^{-1}$ showed the rocking vibration of the $-\mathrm{C}-\mathrm{H}$ band in cellulose, which is typical of $\beta$-glycosidic linkage between glucose units. The peak at $1059 \mathrm{~cm}^{-1}$ is assigned to -C-O-group of secondary alcohols and ethers functions existing in the cellulose chain backbone. The band at $1162 \mathrm{~cm}^{-1}$ ascribed to the $-\mathrm{C}-\mathrm{O}-\mathrm{C}$ - stretch of the $\beta$-1,4-glycosidic linkage is prominent for cellulose samples. The peak at $1434 \mathrm{~cm}^{-1}$ indicated the asymmetric bending of the $-\mathrm{CH}_{2}$ group. This showed the intermolecular hydrogen attraction at the $\mathrm{C}_{6}$ group [28]. The peaks at 2901 and $1372 \mathrm{~cm}^{-1}$ represented stretching and deformation vibrations of $\mathrm{C}-\mathrm{H}$ group in glucose unit. The broad absorption peak in the range of 3000 to $3500 \mathrm{~cm}^{-1}$ was assigned to the stretching of the $\mathrm{H}$-bonded $-\mathrm{OH}$ groups. As can be seen in Figure 3 where the FTIR spectra before and after ultrasonic treatment were not much different, the ultrasonic vibration does not affect the structure of cellulose.

3.3. Thermal Analysis. The thermal stability of lignin and cellulose which were extracted from rice straw was determined by TG-DTA on a simultaneous thermal analyzer (STA 625). The apparatus was continually flushed with nitrogen. The sample was heated from 30 to $800^{\circ} \mathrm{C}$ at a rate of $10^{\circ} \mathrm{C} \cdot \mathrm{min}^{-1}$. Figure 4 illustrates the thermograms of lignin and cellulose (Figure 4) obtained by $2 \mathrm{M} \mathrm{NaOH}$, at $90^{\circ} \mathrm{C}$, for $1.5 \mathrm{~h}$, with sonication time of $30 \mathrm{~min}$. Results showed that lignin and cellulose decreased about $4.3 \%$ and $4.8 \%$ by weight at $130^{\circ} \mathrm{C}$, respectively. This is the amount of water adsorbed by lignin and cellulose, in other words, the moisture content of lignin and cellulose. The $5 \%$ degradation of lignin and cellulose was shown at temperatures of $250^{\circ} \mathrm{C}$ and $230^{\circ} \mathrm{C}$, respectively. The relatively high thermal stability of lignin in this study can be explained by the larger molecular weight. The current results were in good agreement with the thermal stability of lignin from wheat straw, in which the thermal stability increased with the molecular weight [29]. The decomposition temperature of lignin was higher than that of cellulose, which may be due to the aromatic structure of lignin. However, lignin had the decomposition temperature of $50 \%$ by weight about $326^{\circ} \mathrm{C}$, which was lower than cellulose (nearly $410^{\circ} \mathrm{C}$ ). Cyclic oxidation reactions occur at high temperature; the decomposition products from cellulose have higher thermal stability than that from lignin. The decomposition temperature of over $80 \%$ by weight of lignin and cellulose is above $500^{\circ} \mathrm{C}$.

In addition, ultrasound could increase thermal stability of lignin and cellulose. The decomposition temperature of cellulose extracted by alkaline method without ultrasound is lower 


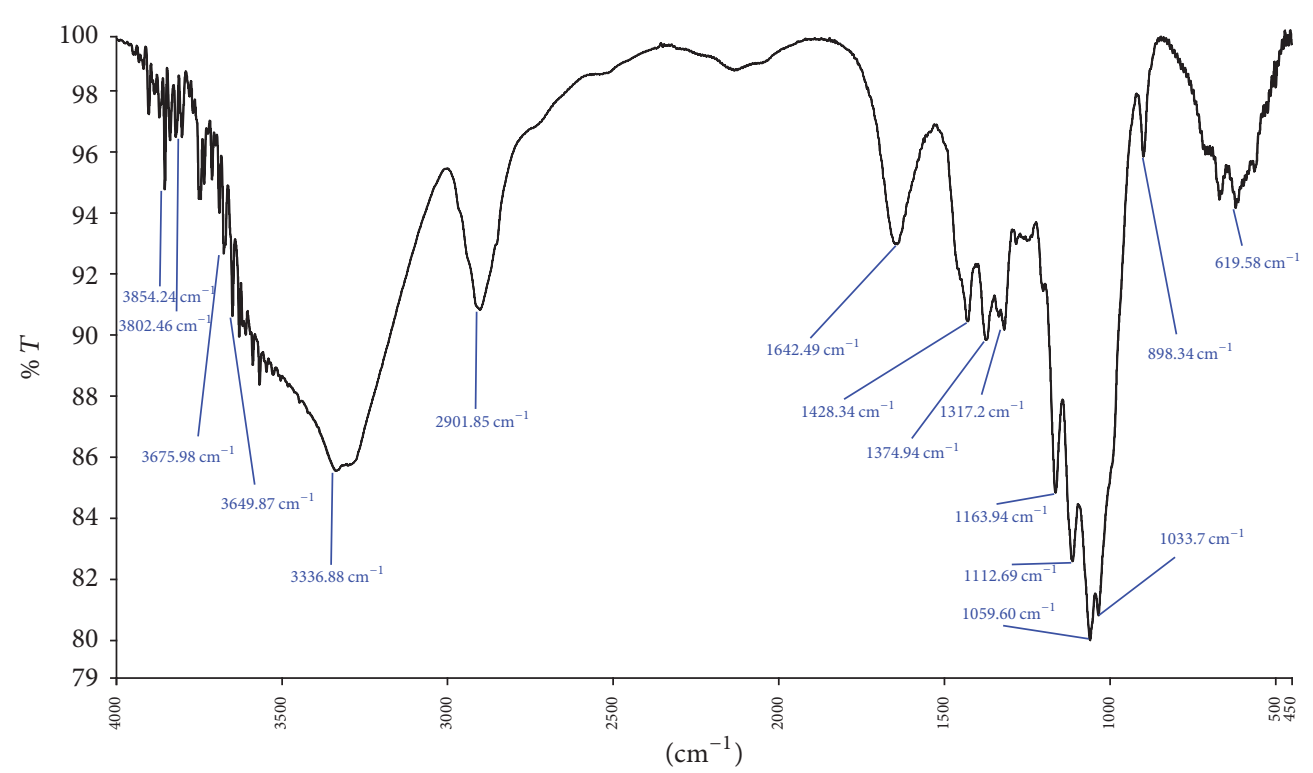

(a)

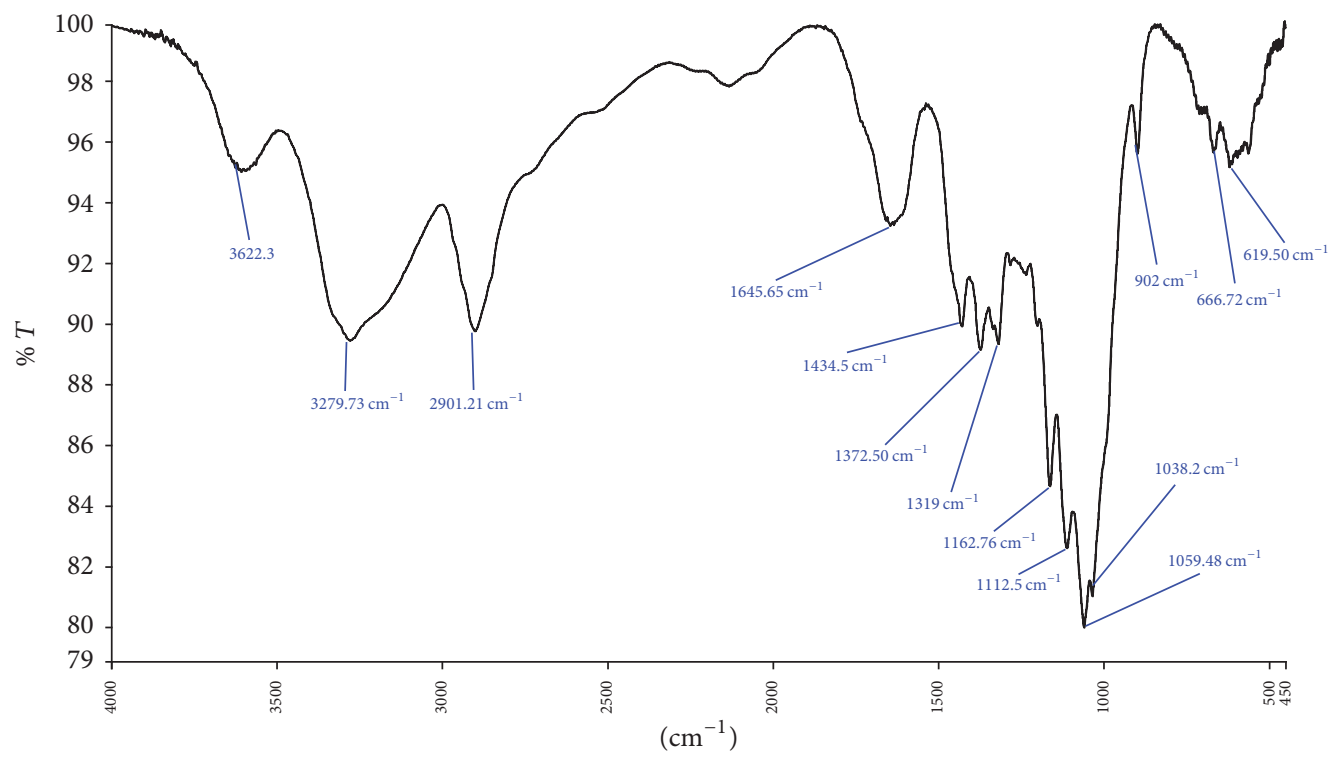

(b)

FIGURE 3: The FTIR spectrum of the cellulose extracted from rice straw without ultrasound (a) and using the ultrasound-assisted alkaline extraction method (b).

than that extracted by ultrasound-assisted alkaline treatment method (Figure 4). It can be seen that the decomposition temperature of $50 \%$ by weight was only $320^{\circ} \mathrm{C}$ for cellulose extracted by alkaline method without ultrasound.

\section{Conclusion}

The obtained results indicated that ultrasound irradiation in alkaline medium with high concentration at high temperature promoted the extraction of lignin and cellulose from rice straw, and their yields increased with sonication time from 10 to $30 \mathrm{~min}$ under the conditions used. Lignin obtained by ultrasound-assisted alkaline extraction method showed a higher molecular weight than that of lignin extracted without ultrasonic irradiation and lignin had a high purity. The ultrasound-assisted alkaline extraction method did not cause significant changes in lignin and cellulose composition and their structure, but ultrasound could increase thermal stability of lignin and cellulose. This is of major importance from the industrial point of view and makes the ultrasoundassisted alkaline extraction process very advantageous. 


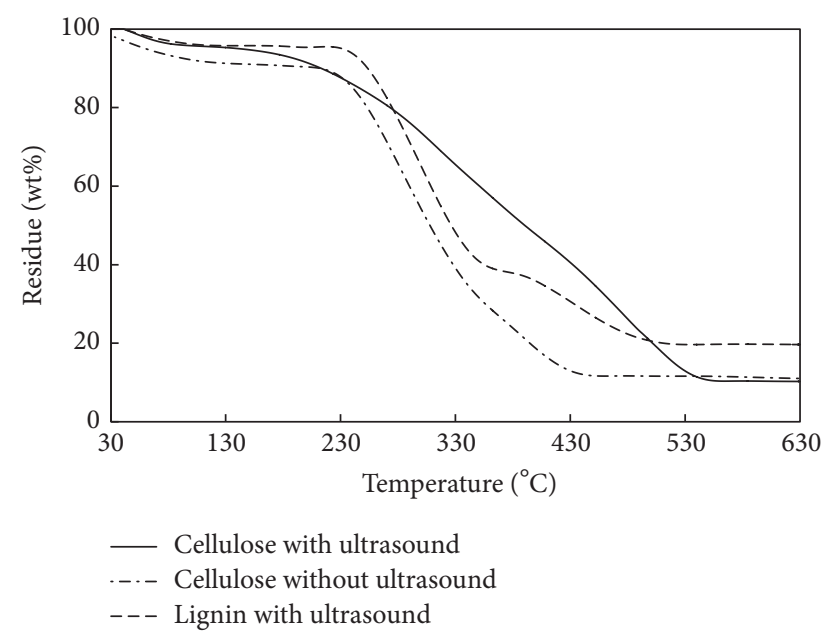

FIGURE 4: TGA curves of cellulose and lignin obtained with and without ultrasound-assisted alkaline extraction method.

\section{Conflicts of Interest}

The authors declare that there are no conflicts of interest.

\section{Acknowledgments}

This research is supported by State Grant ĐTĐL.CN-07/15.

\section{References}

[1] J. Kim, S. Yun, and Z. Ounaies, "Discovery of cellulose as a smart material," Macromolecules, vol. 39, no. 12, pp. 4202-4206, 2006.

[2] B. Zhang, J. Azuma, and H. Uyama, "Preparation and characterization of a transparent amorphous cellulose film," RSC Advances, vol. 5, pp. 2900-2907, 2015.

[3] S. Xiao, B. Liu, Y. Wang, Z. Fang, and Z. Zhang, "Efficient conversion of cellulose into biofuel precursor 5-hydroxymethylfurfural in dimethyl sulfoxide-ionic liquid mixtures," Bioresource Technology, vol. 151, pp. 361-366, 2014.

[4] D. Watkins, M. Nuruddin, M. Hosur, A. Tcherbi-Narteh, and S. Jeelani, "Extraction and characterization of lignin from different biomass resources," Journal of Materials Research and Technology, vol. 4, no. 1, pp. 26-32, 2015.

[5] M. Mascal and E. B. Nikitin, "Direct, high-yield conversion of cellulose into biofuel," Angewandte Chemie International Edition, vol. 47, no. 41, pp. 7924-7926, 2008.

[6] L. Brinchi, F. Cotana, E. Fortunati, and J. M. Kenny, "Production of nanocrystalline cellulose from lignocellulosic biomass: technology and applications," Carbohydrate Polymers, vol. 94, no. 1, pp. 154-169, 2013.

[7] F. A. D. Santos, G. C. V. Iulianelli, and M. I. B. Tavares, "The use of cellulose nanofillers in obtaining polymer nanocomposites: properties, processing, and applications," Materials Sciences and Applications, vol. 7, pp. 257-294, 2016.

[8] D. Min, S. W. Smith, H. Chang, and H. Jameel, "Influence of isolation condition on structure of milled wood lignin characterized by quantitative $13^{\circ} \mathrm{C}$ nuclear magnetic resonance spectroscopy," BioResources, vol. 8, no. 2, pp. 1790-1800, 2013.
[9] S. S. Mankar, A. R. Chaudhari, and I. Soni, "Lignin in phenolformaldehyde adhesives," International Journal of Knowledge Engineering, vol. 3, no. 1, pp. 116-118, 2012.

[10] N. Magnus and E. Håkan, "Lignin: recent advances and emerging applications," Current Opinion in Colloid \& Interface Science, vol. 19, no. 5, pp. 409-416, 2014.

[11] B. Podkościelna, M. Goliszek, and O. Sevastyanova, "New approach in the application of lignin for the synthesis of hybrid materials," Pure and Applied Chemistry, vol. 89, no. 1, pp. 161-171, 2017.

[12] L. Conzatti, F. Giunco, P. Stagnaro et al., "Composites based on polypropylene and short wool fibres," Composites Part A: Applied Science and Manufacturing, vol. 47, pp. 165-171, 2013.

[13] J. Liu and K. Wang, "Study on technology optimization of lignin removalin cellulose extraction from wheat bran by combination of ultrasound and hydrogen peroxide," Biotechnology, vol. 15, no. 6, pp. 135-140, 2016.

[14] O. Mahnaz, S. Ahmad, A. Hossein, and T. Partovi, "Extraction of lignins using a modified dioxane method and an ionic liquid and comparative molecular weight and structural studies by chromatography and ${ }^{13}$ C NMR spectroscopy, techniques," Techniques, Modern Chemistry, vol. 2, no. 5, pp. 36-40, 2014.

[15] M. A. T. Hansen, J. B. Kristensen, C. Felby, and H. Jørgensen, "Pretreatment and enzymatic hydrolysis of wheat straw (Triticum aestivum L.) - The impact of lignin relocation and plant tissues on enzymatic accessibility," Bioresource Technology, vol. 102, no. 3, pp. 2804-2811, 2011.

[16] J. Madeleine and D. Zhang, "Effect of ultrasound on lignocellulosic biomass as a pretreatment for biorefinery and biofuel applications," Industrial \& Engineering Chemistry Research, vol. 52, no. 10, pp. 3563-3580, 2013.

[17] E. Anna and H. Zdenka, "An overview on the application of ultrasound in extraction, separation and purification of plant polysaccharides," Central European Journal of Chemistry, vol. 8, no. 2, pp. 243-257, 2010.

[18] K. O. Reddy, C. Uma Maheswari, E. Muzenda, M. Shukla, and A. V. Rajulu, "Extraction and characterization of cellulose from pretreated ficus (peepal tree) leaf fibers," Journal of Natural Fibers, vol. 13, no. 1, pp. 54-64, 2016.

[19] N. Ngadi and N. Shahirah Rusli, "Ultrasound-assisted extraction of lignin from oil palm frond," Jurnal Teknologi, vol. 67, no. 4, pp. 67-70, 2014.

[20] A. Ranjan, S. Singh, R. S. Malani, and V. S. Moholkar, "Ultrasound-assisted bioalcohol synthesis: review and analysis," RSC Advances, vol. 6, no. 70, pp. 65541-65562, 2016.

[21] B. C. Saha and M. A. Cotta, "Ethanol production from alkaline peroxide pretreated enzymatically saccharified wheat straw," Biotechnology Progress, vol. 22, no. 2, pp. 449-453, 2006.

[22] M. G. Jackson, "Review article: the alkali treatment of straws," Animal Feed Science and Technology, vol. 2, no. 2, pp. 105-130, 1977.

[23] R. R. Spencer, D. E. Aikin, and J. Anim, "Rumen microbial degradation of potassium hydroxide treated coastal Bermudagrass leaf blades examined by electron microscopy," Journal of Animal Science, vol. 51, pp. 1189-1196, 1980.

[24] R. Sun and J. Tomkinson, "Comparative study of lignins isolated by alkali and ultrasound-assisted alkali extractions from wheat straw," Ultrasonics Sonochemistry, vol. 9, no. 2, pp. 85-93, 2002.

[25] B. Xiaoa, X. F. Suna, and R. C. Sun, "Chemical, structural, and thermal characterizations of alkali-soluble lignin and hemicelluloses, and cellulose from maize stems, rye straw, and rice 
straw," Polymer Degradation and Stability, vol. 74, no. 2, pp. 307319, 2001.

[26] A. Yoshioka, T. Seino, M. Tabata, and M. Takai, "Homolytic scission of interunitary bonds in lignin induced by ultrasonic irradiation of MWL dissolved in dimethylsulfoxide," Holzforschung, vol. 54, no. 4, pp. 357-364, 2000.

[27] R. Sun, J. M. Lawther, W. B. Banks, and B. Xiao, "Effect of extraction procedure on the molecular weight of wheat straw lignins," Industrial Crops and Products, vol. 6, no. 2, pp. 97-106, 1997.

[28] V. Kumar and D. Yang, "Preparation, characterization, and tableting properties of a new cellulose-based pharmaceutical aid," International Journal of Pharmaceutics, vol. 235, pp. 129140, 2002.

[29] C. A. Wottitz, C. E. Lopez Pasquali, and H. A. Herrera, "Thermal decomposition of Algarrobo Negro (Prosopis nigra). Wood and its main components: lignin, alpha cellulose and hemicelluloses," Latin American Applied Reseach, vol. 31, pp. 3740, 2001. 

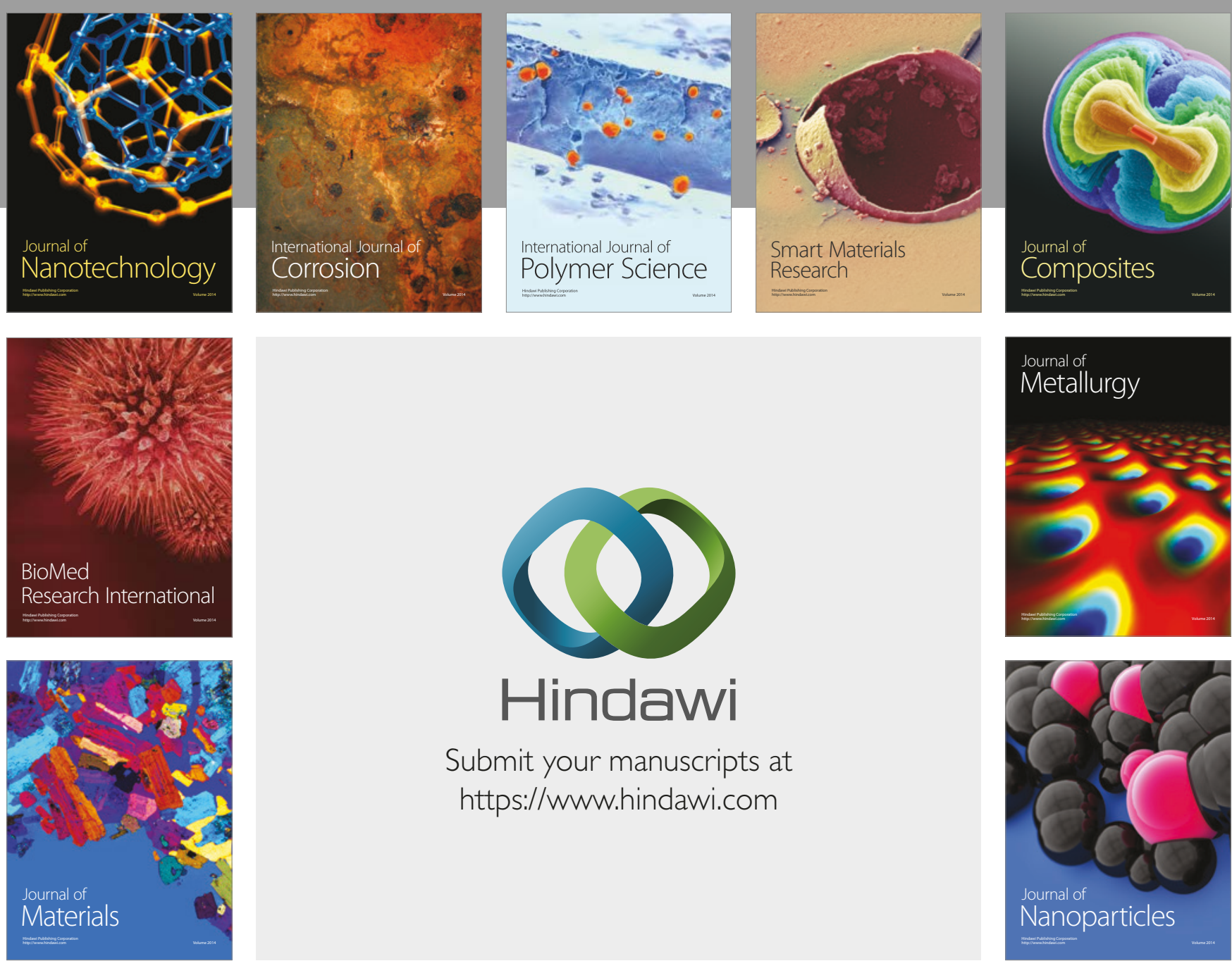

\section{Hindawi}

Submit your manuscripts at

https://www.hindawi.com
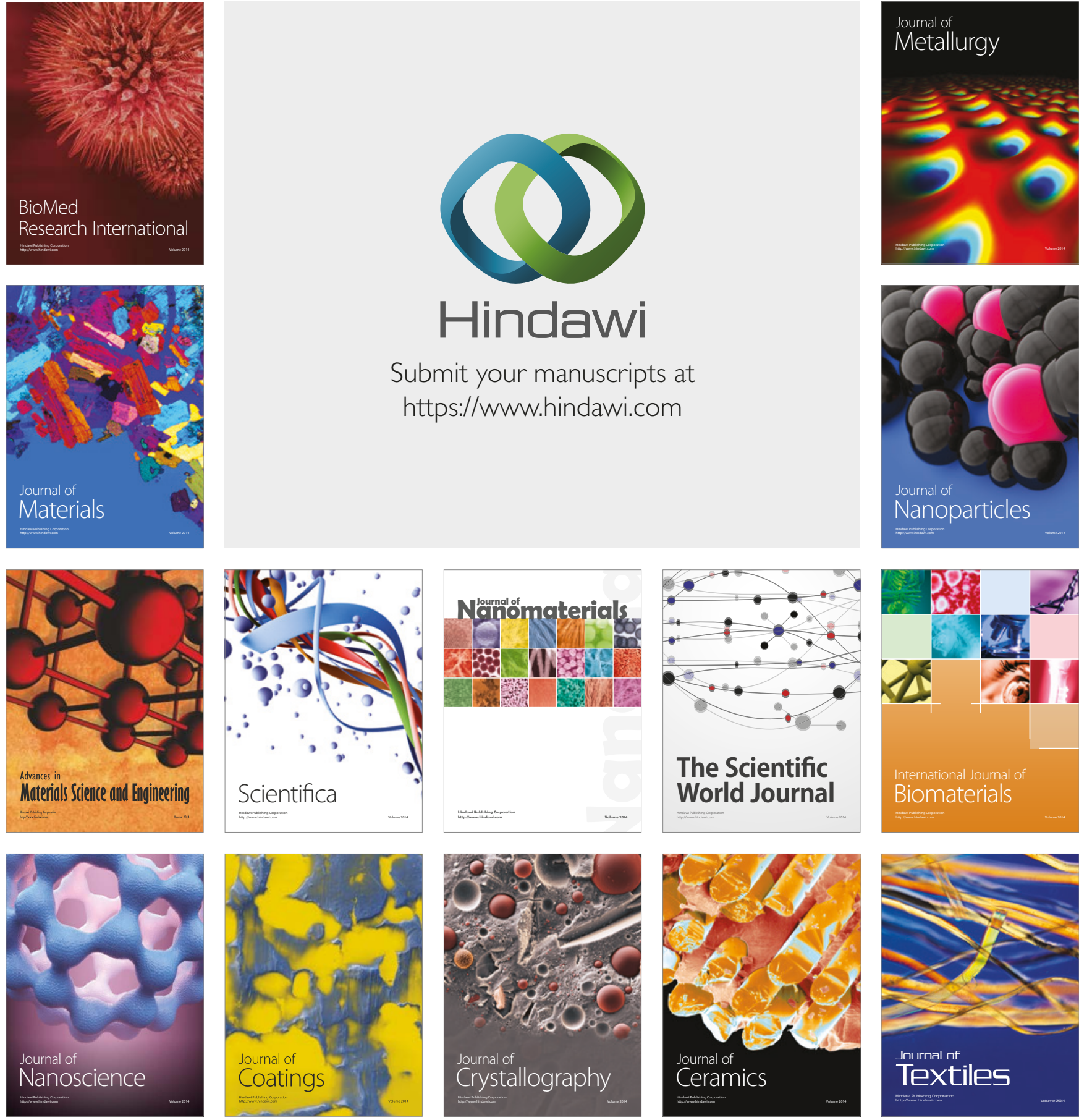

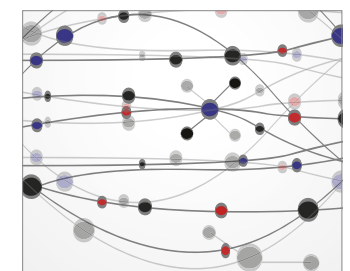

The Scientific World Journal
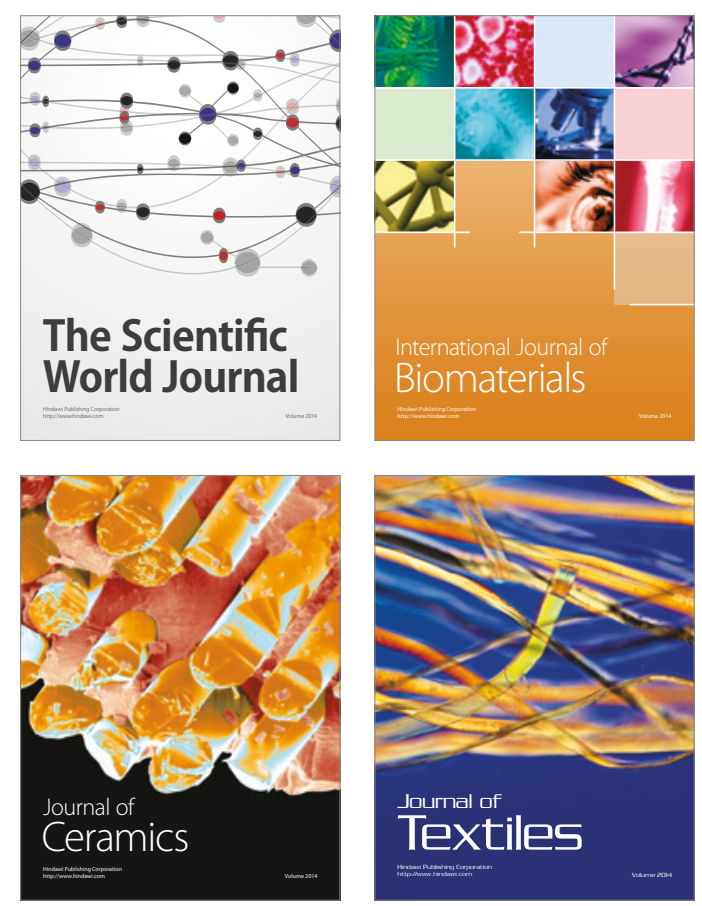